\title{
DESEMPENHO E CARACTERÍSTICAS DE CARCAÇA DE CORDEIROS SUFFOLK ALIMENTADOS COM DIFERENTES VOLUMOSOS ${ }^{1}$
}

\author{
PERFORMANCE AND CARCASS TRAITS OF SUFFOLK LAMBS FED \\ WITH DIFFERENT ROUGHAGES ${ }^{1}$
}

\author{
Eduardo Antonio da Cunha ${ }^{2}$ Mauro Sartori Bueno ${ }^{3}$ Luiz Eduardo dos Santos ${ }^{3}$ \\ Domingos Sanchez Roda ${ }^{2}$ Ivani Pozar Otsuk ${ }^{4}$
}

\section{RESUMO}

Cordeiros da raça Suffolk, desmamados aos 60 dias e confinados, foram alimentados com silagem de milho, silagem de sorgo granífero ou feno de Coast cross (Cynodon dactylon $L$. Pears) e ração concentrada (3,5\% do peso vivo), com o objetivo de avaliar seu desempenho, a proporção dos componentes-nãocarcaça e o rendimento e características das suas carcaças. Foi utilizado um delineamento completamente casualizado em esquema fatorial (três alimentos volumosos e dois sexos). Os animais alimentados com silagem de milho ou de sorgo mostraram maior $(P<0,05)$ ganho médio diário de peso $(295 e$ $294 \mathrm{~g})$ e menor $(P<0,05)$ idade média de abate (119 e 118 dias) que os alimentados com feno (241g e 129 dias). Os machos mostraram maior $(P<0,05)$ ganho de peso diário $(301$ e $252 \mathrm{~g}) e$ menor $(P<0,05)$ idade ao abate $(117$ e 127 dias) que as fêmeas. Os componentes não-carcaça, rendimento de carcaça e de seus cortes, a espessura da gordura subcutânea e grau de gordura não foram afetados $(P>0,05)$ pelo tipo de alimento, contudo, os animais alimentados com silagem de milho apresentaram carcaças com maior $(P<0,05)$ porcentagem de gordura $(18,7$, 16,7 e 17,5\%) e compacidade $(241,232$ e $231 \mathrm{~g} / \mathrm{cm})$ que os demais e menor $(P<0,05)$ proporção de músculo $(59,5,61,1$ e $60,6 \%)$ que os alimentados com a silagem de sorgo. Cordeiras apresentaram carcaças com maior $(P<0,05)$ proporção de gordura $(19,0$ e 16,3\%) e menor $(P<0,05)$ de ossos $(21,0$ e $22,9 \%)$, sem diferença significativa $(P>0,05)$ na proporção de músculos $(60,0$ e 60,7\%). A silagem de sorgo pode substituir a silagem de milho para cordeiros confinados, contudo o uso do feno de gramínea reduz o seu desempenho.

Palavras-chave: ovino, alimentação, silagem de milho, silagem de sorgo, feno, ganho de peso.

\section{SUMMARY}

Suffolk lambs, weaned at 60 days, were raised in slatted floor pens and fed corn silage, sorghum silage or Coast cross hay (Cynodon dactylon L. Pears) plus concentrate ration (3,5\% of live weight) to evaluate their performance, proportion of non-carcass components and carcass dressing and traits. A completely randomized design in a factorial arrangement (tree roughage feed $X$ two sexes) was used. Lambs fed corn silage or sorghum silage showed greater $(P<0.05)$ daily gain $(292$ and $294 \mathrm{~g})$ and smaller $(P<0.05)$ age at slaughter (119 and 118 days) than hay fed lambs (241g and 129 days). Male lambs showed greater $(P<0.05)$ daily liveweight gain $(301$ and $252 \mathrm{~g})$ and smaller $(P<0.05)$ slaughter age $(117$ and 127 days) than females. The non-carcass components, carcass dressing and joints percentage, subcutaneous fat thickness and fat score did not show differences $(P>0.05)$ between feeds, although, lambs fed corn silage showed greater $(P<0.05)$ percentage of fat $(18.7,16.7$ and $17.5 \%)$ and more compact $(P<0.05)$ carcasses $(241,232$ and $231 \mathrm{~g} / \mathrm{cm})$ than the other two feeds and smaller $(P<0.05)$ percentage of lean (59.5, 61.1 and 60.6\%) than lambs fed sorghum silage. Female lambs showed greater $(P<0.05)$ percentage of fat $(19.0$ and $16.3 \%)$ and smaller $(P<0.05)$ percentage of bones (21.0 and 22.9\%) in carcasses than males, without effect $(P>0.05)$ in proportion of muscle (60.0 and $60.7 \%)$. Sorghum silage can replace corn silage for feedlot lambs, but grass hay feeding worsens their performance.

Key words: feeding, hay, live weight gain, sheep, corn silage, sorghum silage.

\section{INTRODUÇÃO}

Face à crescente demanda de carne ovina no Estado de São Paulo, tem aumentado significativamente $\mathrm{o}$ interesse pela produção de animais para abate, com ênfase em cordeiros, com até 21 semanas de idade, que possibilitam a

\footnotetext{
${ }^{1}$ Projeto financiado pela FAPESP. Odessa, SP. E-mail: ceam@izsp.br. Autor para correspondência.

${ }^{3}$ Pesquisador Científico do Centro de Nutrição e Alimentação Animal, Instituto de Zootecnia.

${ }^{4}$ Pesquisadora Científica do Centro de Métodos Quantitativos, Instituto de Zootecnia.
}

${ }^{2}$ Pesquisador Científico do Centro de Etologia, Ambiência e Manejo, Instituto de Zootecnia, Rua Heitor Penteado, 56, 13460-000, Nova 
obtenção de carcaças de excelente qualidade. Para que a produção ovina seja técnica e economicamente viável é necessário, entre outros fatores, que a alimentação dos animais apresente o menor custo possível, sem que haja prejuízo no valor nutritivo da dieta, visto que a qualidade e quantidade do alimento ingerido são fatores determinantes da maior ou menor disponibilidade de nutrientes para o processo fisiológico do animal e, conseqüentemente, do seu desempenho (SANTOS, 1995).

A produção de carne de cordeiro deve utilizar tecnologia adequada, aproveitando-se o potencial de crescimento dos ovinos jovens, utilizando-se, além de animais com bom potencial para ganho de peso, uma alimentação adequada (SIQUEIRA, 1996). Segundo SANTOS (1995), uma das maneiras de se obter bom desempenho com ovinos, a custos economicamente viáveis, é pelo uso de forragem volumosa de boa qualidade. As silagens têm boa aceitabilidade por ovinos, destacando-se as de milho e sorgo granífero. CHESTNUTT (1992) obteve bons resultados na terminação de cordeiros alimentados com silagem de milho e, de acordo com SUSIN (1996), a silagem de milho é um excelente alimento para a produção intensiva de cordeiros, porém se faz necessária uma suplementação protéica e energética.

A silagem de sorgo granífero apresenta-se como uma opção à silagem milho pela suas excelentes características fermentativas e conteúdo energético. ZAGO et al. (1989) compararam o desempenho de vacas em lactação alimentadas com silagem de milho ou sorgo e não observaram diferença na produção de leite ou no consumo de matéria seca. $\mathrm{O}$ valor nutritivo dessas silagens foi avaliado com ovinos e mostrou não haver diferença no consumo voluntário da matéria seca e na digestibilidade aparente da matéria seca (ZAGO \& RIBAS, 1989). Feno de gramíneas é outra opção de alimento volumoso conservado que pode ser utilizado para cordeiros em confinamento. Contudo sua composição bromatológica e, principalmente, seu conteúdo energético e protéico é muito variável em função da idade de corte da forrageira.

O peso vivo de abate de cordeiros deve ser ao redor de $30 \mathrm{~kg}$ pois resulta em carcaças adequadas ao mercado consumidor (BUENO et $\boldsymbol{a l}$. 1998). Devido ao dimorfismo sexual, fêmeas depositam gordura mais precocemente nas carcaças (MERSMANN, 1990) e nos componentes nãocarcaça (WOOD et $\boldsymbol{a l} .$, 1980) que machos. Em razão disso, o peso de abate de fêmeas dever ser inferior aos dos machos devido, também, à sua menor capacidade de ganho de peso (MUWALLA et al. 1998).
O objetivo deste trabalho foi avaliar o desempenho, a proporção dos componentes nãocarcaça, o rendimento e as características de carcaça de cordeiros alimentados com volumosos conservados, normalmente utilizados na alimentação animal, visando identificar aquele mais adequado à produção de cordeiros para abate precoce.

\section{MATERIAL E MÉTODOS}

Foram utilizados 19 cordeiras e 19 cordeiros não castrados, da raça Suffolk, desmamados em média com $60 \pm 1,9$ dias e alocados aleatoriamente em baias coletivas, com piso ripado suspenso, na Unidade de Ovinos do Instituto de Zootecnia em Nova Odessa, SP. A alimentação constou de volumoso a vontade e ração concentrada, composta de milho triturado $(50 \%)$, farelo de soja (19\%), farelo de algodão (15\%), farelo de trigo (13\%), sal (1\%), minerais $(0,5 \%)$ e calcita $(1,5 \%)$ na quantidade de $3,5 \%$ do peso dos animais, corrigido a cada 14 dias.

Três diferentes volumosos conservados foram avaliados: silagem de milho, silagem de sorgo granífero e feno de Coast cross (Cynodon dactylon L. Pears). A sua composição bromatológica encontra-se na tabela 1 . Os animais foram pesados no início e final do experimento (peso final) e em intervalos de 14 dias, sempre pela manhã, antes da alimentação matinal, tendo sido encaminhados aos abate quando atingiram, aproximadamente, $33 \mathrm{e}$ $35 \mathrm{~kg}$ de peso vivo, para fêmeas e machos, respectivamente. Após jejum de alimentos sólidos por 24 horas, foram pesados novamente (peso ao abate) e abatidos. Foram pesados o sangue, as patas, a pele e a cabeça; amarrou-se o esôfago e o reto e pesaram-se as vísceras cheias. $\mathrm{O}$ conjunto pulmãotraquéia-coração, o sistema digestivo (SD) cheio e o fígado foram separados e pesados. A gordura circundante do sistema digestivo foi separada e pesada, sendo denominada gordura mesentérica. Os rins foram retirados das carcaças quentes juntamente com a sua gordura circundante, foram separados e

Tabela 1 - Teores de matéria seca (MS), proteína bruta (PB), fibra em detergente ácido $(\mathrm{FDN})$, cálcio $(\mathrm{Ca})$ e fósforo $(\mathrm{P})$ dos alimentos utilizados.

\begin{tabular}{|c|c|c|c|c|c|}
\hline \multirow[t]{2}{*}{ Alimentos } & MS & $\mathrm{PB}$ & FDN & $\mathrm{Ca}$ & $\mathrm{P}$ \\
\hline & $\%$ & \multicolumn{4}{|c|}{$\% \mathrm{MS}$} \\
\hline Silagem de milho & 30,1 & 7,6 & 59,1 & 0,21 & 0,19 \\
\hline Silagem de sorgo & 31,3 & 9,2 & 63,3 & 0,29 & 0,21 \\
\hline Feno de coast cross & 92,2 & 7,5 & 77,9 & 0,28 & 0,18 \\
\hline Ração concentrada & 87,4 & 19,6 & 10,5 & 0,76 & 0,55 \\
\hline
\end{tabular}


pesados e a gordura denominada de perirenal. O SD foi esvaziado e determinou-se o peso do SD vazio e vísceras vazias. As carcaças foram pesadas e mediuse o pH 15 minutos após o abate ( $\mathrm{pH}$ 0), através de pHmetro com eletrodo de penetração, no músculo longissimus dorsi.

As carcaças foram armazenadas a temperatura de $3^{\circ} \mathrm{C}$ por 48 horas e pesadas novamente para determinação do rendimento de carcaça fria ou comercial. Nessa ocasião, mediu-se novamente o $\mathrm{pH}(\mathrm{pH} 48)$ no mesmo local. Subtraiuse o peso do conteúdo gastrintestinal do peso ao abate dos animais e determinou-se peso vazio e o rendimento verdadeiro. Atribuiu-se nota de um a cinco para o grau de cobertura da gordura subcutânea das carcaças, sendo um fraco e cinco excessivo, e mediu-se a largura da garupa (distância máxima entre os trocânteres de ambos os fêmures ).

As carcaças foram cortadas ao meio e na meia carcaça esquerda mensurou-se o comprimento interno (da sínfese ísquio-pubiana até a primeira costela), a profundidade do tórax (largura máxima do tórax, entre as extremidades distais dos processos espinhosos da terceira e quarta vértebras torácicas e a inserção da terceira e quarta costelas no esterno, medido externamente), o comprimento da perna (distância entre o trocânter maior do fêmur até a junção tarso-metatarsal) e a circunferência da perna (perímetro da perna em sua largura máxima). A meia carcaça esquerda foi pesada e separada em dianteiro (pescoço, membro anterior e cinco costelas), traseiro (perna, garupa, lombo separado do dianteiro entre a quinta e sexta costelas) e costilhar (costela, a partir da sexta, separadas do traseiro a uma distância de, aproximadamente, dois centímetros da coluna vertebral, mais os músculos abdominais). Nesses cortes, efetuou-se a separação física de seus componentes em ossos, gordura e músculos, os quais foram pesados e expressos como porcentagem dos cortes ou da meia-carcaça. A área do músculo longissimus dorsi (olho de lombo), medida através de gabarito padrão transparente quadriculado $\left(0,64 \mathrm{~cm}^{2} /\right.$ célula $)$, e a espessura da gordura subcutânea foram mensuradas no corte realizado entre a $12^{\mathrm{a}}$ e $13^{\mathrm{a}}$ costelas. A compacidade das carcaças foi conseguida através da relação entre o peso da carcaça fria e comprimento interno $(\mathrm{kg} / \mathrm{cm})$.

\section{Utilizou-se um}

delineamento inteiramente ao acaso em esquema fatorial (3X2), com três alimentos volumosos e dois sexos. Na avaliação de desempenho animal (ganho de peso diário e idade de abate) o peso inicial fez parte do modelo e nos componentes não-carcaça e características de carcaça o peso de abate entrou no modelo matemático:

$$
\mathrm{Y}_{\mathrm{ijk}}=\mu+\mathrm{v}_{\mathrm{i}}+\mathrm{s}_{\mathrm{j}}+\mathrm{vs}_{\mathrm{ij}}+\beta\left(\mathrm{x}_{\mathrm{ijk}}-\mathrm{x}\right)+e,
$$

onde: $Y_{\mathrm{ijk}}$ é o valor da observação referente à repetição $\mathrm{k}$, da combinação do nível i dos alimentos volumosos com nível j de sexo; $\mu$ é a média geral; $v_{i}$ é o efeito do tipo de alimento de volumoso; $\mathrm{s}_{\mathrm{j}}$ é o efeito do sexo do cordeiro; $v_{\mathrm{ij}}$ é o efeito da interação tipo de alimento volumoso com o sexo; $\beta$ é o coeficiente de regressão linear; $\mathrm{x}_{\mathrm{ijk}}$ é o peso inicial ou peso de abate e e é o erro experimental. O número de repetições por tratamento foi, para a silagem de milho, sete machos e seis fêmeas, para silagem de sorgo, seis machos e seis fêmeas e, para o feno, seis machos e sete fêmeas.

Em função da natureza dos dados, algumas das variáveis sofreram transformação visando trabalhar-se com os mesmos dentro de uma distribuição normal. Sofreram transformação $\log \mathrm{X}$ a idade de abate (em dias), a porcentagem de gordura perirenal e a porcentagem de ossos da carcaça. A espessura de gordura subcutânea $(\mathrm{mm})$ sofreu transformação 1/X. Utilizou-se o procedimento GLM do SAS e as comparações de médias foram realizadas através do teste de Tukey. Foram efetuadas correlações entre algumas variáveis avaliadas.

\section{RESULTADOS E DISCUSSÃO}

A análise de variância não mostrou interação significativa $(\mathrm{P}>0,05)$ entre tipo de alimentos volumosos e sexos para nenhuma das variáveis avaliadas. A tabela 2 mostra que o tipo de alimento volumoso consumido pelos animais afetou

Tabela 2 - Médias corrigidas para ganho de peso e idade de abate de cordeiros Suffolk, machos e fêmeas, alimentados com diferentes volumosos.

\begin{tabular}{|c|c|c|c|c|c|c|}
\hline \multirow[t]{2}{*}{ Variáveis } & \multicolumn{3}{|c|}{ Volumosos } & \multicolumn{2}{|c|}{ Sexos } & \multirow[t]{2}{*}{$\mathrm{CV}(\%)$} \\
\hline & $\begin{array}{l}\text { Silagem de } \\
\text { milho }\end{array}$ & $\begin{array}{l}\text { Silagem de } \\
\text { sorgo }\end{array}$ & Feno & Macho & Fêmea & \\
\hline Peso inicial $(\mathrm{kg})$ & $16,8^{\mathrm{A}}$ & $16,8^{\mathrm{A}}$ & $17,4 \mathrm{~A}$ & $17,6^{\mathrm{a}}$ & $16,4^{\mathrm{b}}$ & 12,8 \\
\hline Peso final $(\mathrm{kg})$ & $33,7^{\mathrm{A}}$ & $33,8^{\mathrm{A}}$ & $34,2^{\mathrm{A}}$ & $34,9^{\mathrm{a}}$ & $32,9^{\mathrm{b}}$ & 8,5 \\
\hline Ganho de peso diário (g) & $295^{\text {A }}$ & $294^{\text {A }}$ & 241 в & $301^{\mathrm{a}}$ & $252^{\mathrm{b}}$ & 10,1 \\
\hline Idade de abate (dias) & 119 в & 118 в & $129^{\mathrm{A}}$ & 117 b & $127^{\mathrm{a}}$ & 13,6 \\
\hline
\end{tabular}

Médias seguidas de letras maiúsculas nas linhas, referem-se a comparações estatísticas entre os alimentos volumosos avaliados pelo teste de Tukey a $5 \%$ de probabilidade.

Médias seguidas de letras minúsculas nas linhas referem-se a comparações entre sexos através do teste $\mathrm{F}$ a $5 \%$ de probabilidade. 
$(\mathrm{P}<0,05)$ o ganho diário de peso e a idade para alcançar o peso de abate. Os cordeiros alimentados com silagem de milho e de sorgo apresentaram maiores ganhos diários de peso que os alimentados com feno, o que possibilitou seu abate com menor idade. Houve diferença entre sexos $(\mathrm{P}<0,05)$ no ganho diário de peso e idade de abate. $\mathrm{O}$ maior ganho de peso dos animais alimentados com silagens deveu-se ao seu menor teor de FDN e, provavelmente, maior concentração energética das silagens em relação ao feno. Segundo ZAGO \& RIBAS (1989) não há diferença na ingestão de matéria seca $(74,6$ e $79,5 \mathrm{~g} / \mathrm{dia} / \mathrm{UTM})$, nem na digestibilidade aparente com ovinos $(54,3$ e 54,2\%) entre silagens de milho e sorgo, o que pode explicar a similaridade dos resultados encontrados para esses volumosos. Os valores de ganho diário de peso foram superiores aos encontrados por MACEDO $\boldsymbol{e t}$ al. (1999) de 137g/dia, para cordeiros mestiços criados em confinamento e similares aos de BONNA FILHO et al. (1994) de 269,52 a 329,05g/dia, para cordeiros mestiços confinados.

Os componentes não-carcaça, expressos como porcentagem do peso ao abate, podem ser encontrados no tabela 3. Observa-se que esses não variaram $(\mathrm{P}>0,05)$ em função do alimento volumoso consumido, com exceção da gordura perirenal que atingiu valores inferiores $(\mathrm{P}<0,05)$ nos animais alimentados com feno, o que confirma a maior concentração energética das silagens. $\mathrm{O}$ efeito de sexo apresentou diferença significativa $(\mathrm{P}<0,05)$ somente para a porcentagem de gordura perirenal e mesentérica, que foram maiores $(\mathrm{P}<0,05)$ nas fêmeas do que nos machos, o que vai ao encontro dos resultados encontrados por WOOD et al .(1980).

As características de carcaça são apresentadas na tabela 4 . Os rendimentos de carcaça (quente, frio e verdadeiro) não diferiram $(\mathrm{P}>0,05)$ em função do tipo de alimento volumoso consumido, contudo foram maiores $(\mathrm{P}<0,05)$ nas fêmeas do que nos machos. Foi, também, evidenciado por GARCIA et al. (2000) maior rendimento de carcaça para fêmeas em relação aos machos. Os valores de rendimento de carcaça fria foram inferiores aos citados por GARCIA et al. (1997), de 50,13\%, para cordeiros 3/4 Suffolk alimentados com dieta com elevada concentração energética.

A separação física dos componentes da carcaça mostrou que os animais alimentados com silagem de milho apresentaram carcaças mais gordas $(\mathrm{P}<0,05)$ que os demais, porcentagem de músculos inferior $(\mathrm{P}<0,05)$ aos alimentados com silagem de sorgo e porcentagem de ossos semelhantes $(\mathrm{P}>0,05)$ aos outros alimentos volumosos consumidos. As fêmeas apresentaram maior $(\mathrm{P}<0,05)$ porcentagem de gordura na carcaça que os machos, o que concorda com MERSMANN (1990), e menor $(\mathrm{P}<0,05)$ porcentagem de ossos. As correlações negativas entre porcentagem de gordura com porcentagem de músculos $(\mathrm{r}=-0,76)$ e porcentagem de gordura com porcentagem de ossos nas carcaças $(\mathrm{r}=-0,65)$, a baixa correlação entre porcentagem de músculos com a de ossos $(\mathrm{r}=0,01)$ mostram que o aumento na porcentagem de gordura nas carcaças leva à diminuição nas porcentagens de músculos e ossos.

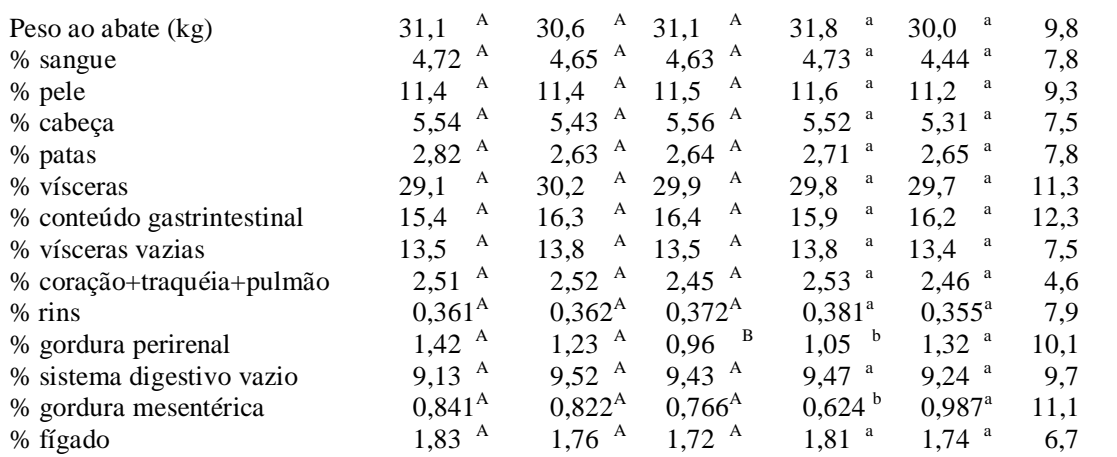

Médias seguidas de letras maiúsculas nas linhas, referem-se a comparações estatísticas entre os alimentos volumosos avaliados pelo teste de Tukey a 5\% de probabilidade.

Médias seguidas de letras minúsculas nas linhas referem-se a comparações entre sexos através do teste $\mathrm{F}$ a $5 \%$ de probabilidade.
A porcentagem dos cortes das carcaças não sofreu efeito do tipo de alimento volumoso consumido ou do sexo $(\mathrm{P}>0,05)$. Os componentes dos cortes, obtidos por separação física, gordura foi sempre superior $(\mathrm{P}<0,05)$ para os animais alimentados com silagem de milho e para as fêmeas. Já os valores de $\mathrm{pH}$ das carcaças mostraram diminuição característica do processo de maturação e mostraram que o teor de 
Tabela 4 - Médias corrigidas para caraterísticas de carcaça de cordeiros Suffolk, machos e fêmeas, alimentados com diferentes volumosos.

\begin{tabular}{|c|c|c|c|c|c|c|}
\hline \multirow[t]{2}{*}{ VARIÁVEIS } & \multicolumn{3}{|c|}{ Volumosos } & \multicolumn{2}{|c|}{ Sexos } & \multirow[t]{2}{*}{$\mathrm{CV}(\%)$} \\
\hline & $\begin{array}{l}\text { Silagem } \\
\text { de milho }\end{array}$ & $\begin{array}{l}\text { silagem } \\
\text { de sorgo }\end{array}$ & feno & macho & fêmea & \\
\hline rendim. quente $(\%)$ & $46,7^{\mathrm{A}}$ & $46,0^{\mathrm{A}}$ & $45,9^{\mathrm{A}}$ & $45,7^{\mathrm{b}}$ & $46,7^{\mathrm{a}}$ & 5,2 \\
\hline rendim. frio $(\%)$ & $44,3^{\mathrm{A}}$ & 43,3 A & $43,5^{\mathrm{A}}$ & $43,1 \quad b$ & $44,3^{\text {a }}$ & 5,4 \\
\hline rendim. verdadeiro (\%) & $52,4^{\text {A }}$ & $51,7^{\mathrm{A}}$ & 52,1 A & 51,3 b & $52,8^{\text {a }}$ & 5,3 \\
\hline osso na carcaça (\%) & 21,7 A & 22,2 A & 22,1 A & $22,9^{\mathrm{a}}$ & 21,0 & 6,1 \\
\hline músculo na carcaça (\%) & 59,5 в & 61,1 A & $60,6^{\mathrm{AB}}$ & $60,7^{\mathrm{a}}$ & $60,0^{\mathrm{a}}$ & 8,6 \\
\hline gordura na carcaça $(\%)$ & $18,7^{\mathrm{A}}$ & $16,7 \quad$ B & 17,5 в & $16,3^{\mathrm{b}}$ & $19,0^{\mathrm{a}}$ & 9,3 \\
\hline traseiro $(\%)$ & 48,1 A & $48,4^{\mathrm{A}}$ & $48,2^{\text {A }}$ & $48,0^{\mathrm{a}}$ & $48,4^{\mathrm{a}}$ & 7,8 \\
\hline osso $(\%)$ & $21,6^{\mathrm{A}}$ & $22,8^{\mathrm{A}}$ & $22,4^{\mathrm{A}}$ & $23,2^{\text {a }}$ & 21,3 b & 10,1 \\
\hline músculo (\%) & $65,6^{\mathrm{A}}$ & $66,2^{A}$ & $65,5^{\mathrm{A}}$ & $65,7^{\mathrm{a}}$ & $65,7^{\mathrm{a}}$ & 6,7 \\
\hline gordura (\%) & $12,6^{\mathrm{A}}$ & 11,4 в & 11,9 в & $10,9 \mathrm{~b}$ & $13,1^{\mathrm{a}}$ & 8,5 \\
\hline dianteiro $(\%)$ & $38,6^{\mathrm{A}}$ & $38,4^{\mathrm{A}}$ & 39,1 A & $39,1^{\text {a }}$ & $38,2^{a}$ & 11,1 \\
\hline osso (\%) & $24,7^{\mathrm{A}}$ & $24,7^{\mathrm{A}}$ & $24,3^{\mathrm{A}}$ & $25,4^{\mathrm{a}}$ & 23,8 & 8,6 \\
\hline músculo $(\%)$ & 54,2 A & $56,4^{\text {A }}$ & 55,1 A & $55,4^{\text {a }}$ & $54,9^{\text {a }}$ & 7,8 \\
\hline gordura (\%) & 21,3 A & 18,8 в & 19,5 в & $18,7 \mathrm{~b}$ & $20,9^{a}$ & 9,6 \\
\hline costilhar $(\%)$ & $13,3^{\mathrm{A}}$ & $13,2^{\mathrm{A}}$ & $12,9^{\mathrm{A}}$ & $12,9^{\mathrm{a}}$ & $13,3^{\text {a }}$ & 9,0 \\
\hline osso $(\%)$ & $12,8^{\mathrm{A}}$ & $13,4^{\mathrm{A}}$ & 12,1 в & $13,8^{\text {a }}$ & 11,7 & 9,7 \\
\hline músculo $(\%)$ & 54,2 A & $56,4^{\text {A }}$ & $55,8^{\mathrm{A}}$ & $56,8^{\text {a }}$ & 53,9 & 8,9 \\
\hline gordura $(\%)$ & 33,3 A & 30,5 в & 30,8 в & $28,2^{b}$ & $34,4^{\mathrm{a}}$ & 8,4 \\
\hline $\mathrm{pH} 0$ & $6,5^{\mathrm{A}}$ & $6,4^{\mathrm{A}}$ & $6,5^{\mathrm{A}}$ & $6,5^{\mathrm{a}}$ & $6,5^{a}$ & 9,6 \\
\hline $\mathrm{pH} 48$ & $5,7^{\mathrm{A}}$ & $5,6^{\mathrm{A}}$ & $5,6^{\mathrm{A}}$ & $5,6^{\mathrm{a}}$ & $5,7^{a}$ & 5,6 \\
\hline olho de lombo $\left(\mathrm{cm}^{2}\right)$ & $12,3^{\mathrm{A}}$ & $11,8^{\mathrm{A}}$ & $11,8^{\mathrm{A}}$ & $12,2^{\mathrm{a}}$ & $11,8^{\mathrm{a}}$ & 6,1 \\
\hline gord. subcutânea (mm) & $1,52^{\mathrm{A}}$ & $1,55^{\mathrm{A}}$ & $1,44^{\mathrm{A}}$ & $1,30^{\mathrm{b}}$ & $1,73^{\mathrm{a}}$ & 10,1 \\
\hline grau de gordura $(0-5)$ & $2,21^{\mathrm{A}}$ & $2,15^{\mathrm{A}}$ & $2,05^{\mathrm{A}}$ & $2,03^{b}$ & $2,27^{\mathrm{a}}$ & 7,4 \\
\hline compacidade $(\mathrm{g} / \mathrm{cm})$ & $241 \mathrm{~A}$ & 232 B & $231 \quad$ B & $233^{\text {a }}$ & $232^{a}$ & 5,9 \\
\hline
\end{tabular}

Médias seguidas de letras maiúsculas nas linhas, referem-se a comparações estatísticas entre os alimentos volumosos avaliados pelo teste de Tukey a $5 \%$ de probabilidade. Médias seguidas de letras minúsculas nas linhas referem-se a comparações entre sexos através do teste $\mathrm{F}$ a $5 \%$ de probabilidade. idade foram similares aos encontrados neste estudo.

O grau de compacidade das carcaças evidenciou que os animais alimentados com silagem de milho apresentaram carcaças mais compactas $(\mathrm{P}<0,05)$ que as dos animais alimentados com silagem de sorgo ou feno. Não houve efeito de sexo $(\mathrm{P}>0,05)$ nesta variável e os valores foram similares aos de MUNIZ et al. (1997) para cordeiros cruzados Corriedale $\mathrm{x}$ Texel, abatidos com 208 dias. As correlações entre compacidade e porcentagem de gordura separável da carcaça $(r=0,52)$, grau de gordura $(\mathrm{r}=0,54)$ e porcentagem de músculos $(\mathrm{r}=-0,22)$ mostraram que a maior deposição de tecidos por unidade de comprimento deveu-se a uma maior deposição de gordura e não de músculos.

As médias corrigidas para medidas de carcaças podem ser encontradas na tabela 5. Não foram evidenciados diferenças estatísticas significativas entre os alimentos volumosos avaliados e sexos, denotando que esses volumosos não alteram estas características.

\section{CONCLUSÕES}

não apresentaram diferenças $(\mathrm{P}>0,05)$ entre alimentos volumosos avaliados, nem entre sexos. Também, a área de olho de lombo, a espessura da gordura subcutânea e o grau de gordura das carcaças foram similares $(\mathrm{P}>0,05)$ entre os alimentos volumosos avaliados. $\mathrm{O}$ efeito do sexo foi significativo $(\mathrm{P}<0,05)$ para a espessura da gordura subcutânea e grau de gordura, que mostraram valores mais elevados para as fêmeas. A correlação entre porcentagem de gordura na carcaça com a espessura da gordura subcutânea $(r=0,57)$ ou com o grau de gordura $(r=0,73)$ mostra que estas variáveis possibilitam inferir adequadamente o teor de gordura separável das carcaças, o que concorda com CUNHA et al., (1999). Os valores para a espessura da gordura subcutânea e grau de gordura encontrados por MACEDO et al. (1997), de 1,5mm e 2,68, respectivamente, para cordeiros cruzados abatidos com 268 dias de
Tabela 5 - Médias corrigidas para medidas de carcaças $(\mathrm{cm})$ de cordeiros Suffolk, machos e fêmeas, alimentados com diferentes volumosos.

\begin{tabular}{lcccccr}
\hline \multirow{2}{*}{ VARIÁVEIS } & \multicolumn{3}{c}{ TRATAMENTO } & \multicolumn{2}{c}{ SEXO } & \multirow{2}{*}{ CV (\%) } \\
\cline { 2 - 5 } & $\begin{array}{l}\text { Silagem } \\
\text { de milho }\end{array}$ & $\begin{array}{c}\text { Silagem } \\
\text { de sorgo }\end{array}$ & Feno & Macho & Fêmea & \\
& $65,2^{\mathrm{A}}$ & $66,1^{\mathrm{A}}$ & $64,8^{\mathrm{A}}$ & $66,2^{\mathrm{a}}$ & $64,5^{\mathrm{a}}$ & 11,1 \\
Comprimento externo & $56,5^{\mathrm{A}}$ & $57,3^{\mathrm{A}}$ & $56,1^{\mathrm{A}}$ & $57,1^{\mathrm{a}}$ & $56,1^{\mathrm{a}}$ & 9,8 \\
Comprimento interno & $32,1^{\mathrm{A}}$ & $31,7^{\mathrm{A}}$ & $31,9^{\mathrm{A}}$ & $31,9^{\mathrm{a}}$ & $31,8^{\mathrm{a}}$ & 8,9 \\
Profundidade torácica & $34,5^{\mathrm{A}}$ & $34,8^{\mathrm{A}}$ & $35,0^{\mathrm{A}}$ & $35,5^{\mathrm{a}}$ & $34,1^{\mathrm{a}}$ & 9,6 \\
Comprimento da perna & $38,9^{\mathrm{A}}$ & $38,4^{\mathrm{A}}$ & $38,1^{\mathrm{A}}$ & $38,9^{\mathrm{a}}$ & $38,0^{\mathrm{a}}$ & 11,2 \\
Circunferência da perna & $19,1^{\mathrm{A}}$ & $19,0^{\mathrm{A}}$ & $19,5^{\mathrm{A}}$ & $19,2^{\mathrm{a}}$ & $19,2^{\mathrm{a}}$ & 10,2 \\
Largura da garupa & & & & & & \\
\hline
\end{tabular}

Médias seguidas de letras maiúsculas nas linhas, referem-se a comparações estatísticas entre os alimentos volumosos avaliados pelo teste de Tukey a $5 \%$ de probabilidade.

Médias seguidas de letras minúsculas nas linhas referem-se a comparações entre sexos através do teste $\mathrm{F}$ a $5 \%$ de probabilidade. 
precoce e o feno de gramínea levou a menor desempenho dos animais e abate mais tardio. As características de carcaça são alteradas pelo tipo de alimento volumoso consumido pelos animais, sendo que a silagem de milho produz carcaças mais gordas e mais compactas.

\section{AGRADECIMENTOS}

Os autores agradecem aos funcionários de apoio à pesquisa científica e tecnológica Paulo Pereira dos Santos, Onofre Martins, José Sperch, José Aparecido de Oliveira, Pedro Joaquim da Silva e Olinda Aparecida de Oliveira Costa, pela valiosa colaboração na execução deste trabalho.

\section{REFERÊNCIAS BIBLIOGRÁFICAS}

BONNA FILHO, A., OTTO, C., LEME, M.C.J., et al. Ganho de peso e características de carcaça de cordeiros confinados e suplementados com diferentes níveis de farinha de peixe em substituição ao farelo de soja. Rev Set Ciênc Agr, Curitiba, v.13, n.1-2, p.183-191, 1994.

BUENO, M.S., CUNHA, E.A., SANTOS, L.E., et al. Avaliação de carcaças de cordeiros Suffolk abatidos com diferentes pesos-vivos. In: REUNIÃO ANUAL DA SOCIEDADE BRASILEIRA DE ZOOTECNIA, 35, 1998, Botucatu. Anais... Botucatu : SBZ, 1998. V.4, 735p. p.573-575.

CUNHA, E.A., BUENO, M.S., SANTOS, L.E., $\boldsymbol{e} \boldsymbol{t} \boldsymbol{a l}$ Correlações entre características de carcaça de cordeiros Suffolk. In: REUNIÃO ANUAL DA SOCIEDADE BRASILEIRA DE ZOOTECNIA, 36, 1999, Porto Alegre. Anais... Porto Alegre : SBZ, 1999. (CD-ROM)

CHESTNUTT, D.M.B. Supplementation of silage-based diets for finishing lambs. Anim Prod, Edinburgh, v.55, n. 2, p.137$145,1992$.

GARCIA, C.A, MONTEIRO, A.L., SAFFI, F.J. Efeito da substituição do milho pela semente de sorgo-vassoura no desempenho de cordeiros confinados. In: REUNIÃO ANUAL DA SOCIEDADE BRASILEIRA DE ZOOTECNIA, 34, 1997, Juiz de Fora. Anais... Juiz de Fora: Sociedade Brasileira de Zootecnia, 1997. V.3, 476p. p.370-372.

GARCIA, I.F, PEREZ, J.RO., OLIVEIRA, M.V. Características de carcaça de cordeiros Texel x Santa Inês e Santa Inês puros, terminados em confinamento, com casca de café como parte da dieta. Rev Bras Zootec, Viçosa, v.29, n.1, p.253260,2000
MACEDO, F.A.F., MARTINS, E.N., SIQUEIRA, E.R., $\boldsymbol{e} t$ al. Cruzamentos e sistemas de terminação na produção de carcaças de crias. In: REUNIÃO ANUAL DA SOCIEDADE BRASILEIRA DE ZOOTECNIA, 34, 1997. Juiz de Fora. Anais... Juiz de Fora : SBZ, 1997. V.1, 479p. p.388-390.

MACEDO, F.A.F., SIQUEIRA, E.R, MARTINS, E.N Desempenho de cordeiros, puros e mestiços, terminados em pastagem e em confinamento. Arq Bras Med Vet Zootec, Belo Horizonte, v.51, n.6, p.583-587, 1999.

MERSMANN, H.J. Metabolic and endocrine control of adipose tissue accretion. In: WOOD, J.D., FISHER, A.V. (ED.). Reducing fat in meat animals. London : Elsevier Science, 1990. 469p. p.101-144.

MUNIZ, E.N.M., PIRES, C.C., SILVA, J.H.S. et al. Crescimento ponderal e características da carcaça de cordeiros de diferentes genótipos. In: REUNIÃO ANUAL DA SOCIEDADE BRASILEIRA DE ZOOTECNIA, 34, 1997, Juiz de Fora. Anais... Juiz de Fora : Sociedade Brasileira de Zootecnia, 1997. V.3, 479p. p.293-295.

MUWALLA, M.M., HARB,M.Y., CROSBY, T.F. Effects of lasalocid and protein levels on performance of Awassi lambs. Small Ruminant research, Amsterdan, v.28, p.15-22, 1998.

SANTOS, L.E. Pastagens para ovinos. In: SIMPÓSIO PAULISTA DE OVINOCULTURA, 4, 1995, Campinas, Anais... Campinas: CATI, 1995. 139p. p.1-18.

SIQUEIRA, E.R. Recria e terminação de cordeiros em confinamento. In: NUTRIÇÃO DE OVINOS, 1, 1996, Jaboticabal. Anais... Jaboticabal : FUNEP, 1996. 258p. p.175-212.

SUSIN, I. Exigências nutricionais de ovinos e estratégias de alimentação. In: NUTRIÇÃO DE OVINOS, 1, 1996, Jaboticabal. Anais... Jaboticabal : FUNEP, 1996. 258p. p.119-141.

WOOD, J.D., MACFIE, H.J.H., POMERY, R.W., et al. Carcas composition in four sheep breeds: the importance of breed and stage of maturity. Anim Prod, v.30, p.135-152, 1980

ZAGO, C.P., RIBAS, T.M. AG2005-E novo híbrido forrageiro para silagem e grãos In: REUNIÃO DA SOCIEDADE BRASILEIRA DE ZOOTECNIA, 34, 1989, Porto Alegre, Anais... Porto Alegre : Sociedade Brasileira de Zootecnia, 1989. 461p. p. 420

ZAGO, C.P, CRUZ, M.E., GOMIDE, J.A. Avaliação do desempenho de vacas leiteiras alimentadas com silagem de milho e de sorgo. In: REUNIÃO DA SOCIEDADE BRASILEIRA DE ZOOTECNIA, 34, 1989, Porto Alegre. Anais... Porto Alegre : Sociedade Brasileira de Zootecnia, 1989. 461p. p.290.

Ciência Rural, v. 31, n. 4, 2001. 